$\begin{array}{ccc}\text { UNIVERSITA } & \text { DEPARTMENT OF } \\ \text { DEGLI STUII } \\ \text { DI TORINO }\end{array}$

\title{
PERSONAL INCOME TAX REFORMS: A GENETIC ALGORITHM APPROACH
}

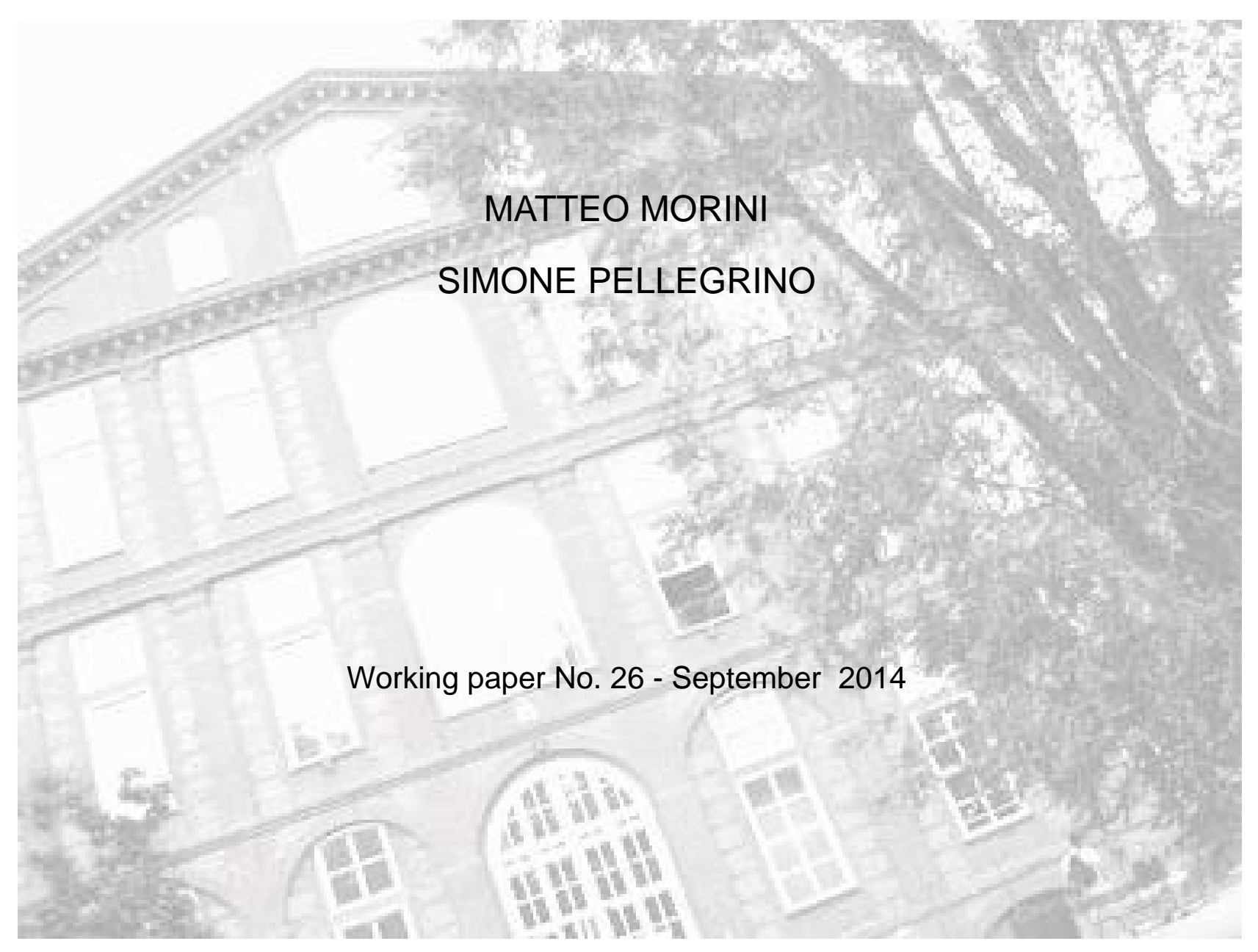




\title{
Personal Income Tax Reforms: a Genetic Algorithm Approach
}

September $10^{\text {th }}, 2014$

\section{Matteo Morini}

ENS Lyon, Institut Rhône-Alpin des Systèmes Complexes (IXXI), Lyon (FR) University of Torino, Department of Economics and Statistics, Torino (IT)

\section{Simone Pellegrino}

University of Torino, Department of Economics and Statistics, Torino (IT)

\begin{abstract}
Given a settled reduction in the present level of tax revenue, and by exploring a very large combinatorial space of tax structures, in this paper we employ a genetic algorithm in order to determine the optimal structure of a personal income tax that allows the maximization of the redistributive effect of the tax, while preventing all taxpayers being worse off than with the present tax structure. We take Italy as a case study.
\end{abstract}

JEL Codes: C63, C81, H23, H24

Keywords: Personal income taxation, Genetic algorithms, Micro-simulation models, Reynolds-Smolensky index, Tax reforms 


\section{Introduction}

Personal income tax (hereafter PIT) around the world is characterized by several parameters that define its structure (marginal tax rates, upper limits of the thresholds, allowances and deductions, as well as tax credits). Applied to the distribution of income observed in a specific country, the PIT structure determines a given tax revenue and a given redistributive effect. Starting from this situation, a Government may want to cut down tax revenue in order to reduce the implicit tax rate on labour, as well as to increase the purchasing power of households; conversely it may want to increase tax revenue in order to reduce net borrowing.

With respect to these arguments, Italy is an important case study: the Italian PIT is very complicated, and its structure incorporates more than thirty parameters. Moreover, in order to increase the purchasing power of the households, the Italian Government recently decided to introduce a money transfer of 640 euros (only) for employees with a PIT gross income in the range of 8-26 thousand euros. This tax measure reduces PIT revenue by about 7 billion euro (5 percent of total revenue). In the 2014 fiscal year, this transfer has been applied for 8 months, and it is expected to be applied for the whole year in 2015; therefore the tax cut will amount to about to 10.5 billion euro, 7 percent of the total revenue.

Is this tax cut allocation the best one the Government could have considered? Or, given a settled reduction in the present tax revenue, how should the tax structure change in order to achieve a specific target? In what follows our target is to maximize the redistributive effect of the tax evaluated on the taxpayers' income distribution, while having no taxpayers lose out with respect to the present tax structure. For several reasons, it is not the case that policy makers consider these questions when thinking of a tax cut. The observed structure of the tax system is indeed the result of several adjustments that have occurred over the past few years, and whether those tax reforms aim at achieving the highest redistributive effect is debatable. Policy makers might usually also consider other targets by finding a compromise between equity and efficiency. In this paper we mainly focus on the equity side of the problem. ${ }^{1}$ This does not imply that we completely forget about the efficiency side; we suggest a few

\footnotetext{
${ }^{1}$ Since the elasticity of labour supply with respect to income decreases with income, note that for the problem under discussion equity and efficiency should both favour a higher reduction of taxes with regard to the bottom deciles of the income distribution.
} 
constraints to the allowable parameters of tax structure in order not to arrive at both trivial and inefficient solutions.

To answer the above question we rely on a static micro-simulation model written in STATA (technical details are available in Pellegrino et al. (2011)) that employs, as input data, those provided by the Bank of Italy in its Survey on Households' Income and Wealth published in 2012 with regard to the 2010 fiscal year. The results of this micro-simulation model are very close to the official statistics made available by the Italian Ministry of Economy and Finance for the 2010 fiscal year, so that this instrument is suitable for the type of empirical analysis we propose.

The static micro-simulation model had to be re-implemented in a more versatile way in order for the kind of analysis we are interested in to be feasible. We then rewrote the set of algorithms defining the structure of Italian personal income tax, as well as the modules of the micro-simulation model evaluating Italian personal income tax in Python, a language that allows the use of parallel computing techniques distributed across multiple nodes. Python also offers an excellent compromise between agility in programming - providing the developers with several libraries optimized for numerical calculations - and computational performance.

We then employed a genetic algorithm, that is a search heuristic inspired by natural selection, well suited to the identification of the most promising solution to the problem under consideration. We were interested in coming up with a reasonable tax structure that inhibits both trivial and inefficient solutions. The genetic algorithm had then to be provided with few specific constraints that had to be obeyed in terms of some parameters of the tax structure. If this were not the case, problematic solutions would appear: for example, having to find the highest redistributive effect with no constraints at all, the genetic algorithm would certainly impose excessively high marginal tax rates on higher income earners, and a zero marginal tax rate on too many of the poorest taxpayers. As a result, a polarization of tax rates and bandwidths of thresholds would appear, and the tax revenue would consequently be too high. Or the genetic algorithm would disproportionately favour high levels of some peculiar tax credits, simply because they are enjoyed by a small group of taxpayers, resulting in a negligible impact on the tax revenue, but awkward preferential treatment of some income groups. 
In order to avoid these unpleasant outcomes, and to minimize the running time of our genetic algorithm, we impose two constraints.

First, we impose a condition that no taxpayers have to be worse off as a result of the tax reform; that is all taxpayers must pay a lower (or, at most, equal) amount of taxes than the present one. As a consequence, since the Italian personal income tax does not allow negative income taxation, and as we are looking for a tax reform with no losing taxpayers, we let the 'no tax' area be greater, or at least equal, to the present one. We also require the highest marginal tax rate as well as the lower limit of the top tax threshold to be lower or at most equal to the present values.

Second, we keep unchanged the rank applied by the present tax structure to certain kind of tax credits: for example, the present tax credit applied to employees is greater than that applied to pensioners, and the one applied to pensioners is greater than that applied to self-employed taxpayers; similarly, the tax credit for tenants is greater with regard to younger ones.

In doing so, we do not allow the genetic algorithm to run free with too 'imaginative' solutions, and we allow it to find the solution in a reasonable amount of time.

Then, we have to define our target: we are interested in obtaining the highest redistributive effect of the tax. To measure it we refer to the Reynolds-Smolensky index, given by the difference between the Gini coefficient for the individuals' pre-tax income distribution and the corresponding concentration coefficient for the post-tax distribution.

We then let the genetic algorithm set up a population of 500 different tax structures, each of them composed of 33 different parameters defining the present structure of the Italian personal income tax, and we let it evolve for hundreds of generations until the desired result has been achieved.

The structure of the paper is as follows. Section 2 describes in greater detail the 2010 structure of the Italian personal income tax, the baseline for our analysis. Section 3 briefly presents how tax progressivity, and the redistributive effect exerted by the tax, can be measured. Section 4 shows the data and the peculiarities of the static microsimulation model employed for simulations. Section 5 first describes how genetic 
algorithms work, and then presents the one used in this work. Section 6 shows the results whilst section 7 offers a conclusion.

\section{The Personal Income Tax in the 2010 Fiscal Year: Technical Details}

Let $x_{i}$ be the personal gross income of taxpayer $i(i=1,2, \ldots, n)$. The 2010 Italian tax law considers two different kinds of deductions: $d_{i}^{1}$ is deduction for the main residence cadastral income; $d_{i}^{2}$ is the sum of deductions for social security contributions and alimonies as well as donations. The taxable income $y_{i}$ is evaluated as:

$$
y_{i}=\left\{\begin{array}{lll}
x_{i}-d_{i}^{1}-d_{i}^{2} & \text { if } & d_{i}^{1}+d_{i}^{2}<x_{i} \\
0 & \text { if } & d_{i}^{1}+d_{i}^{2} \geq x_{i}
\end{array}\right.
$$

From 2007 onwards the rate schedule $S\left(y_{i}\right)$ contemplates 5 thresholds as reported in Table 1.

\section{TABLE 1 AROUND HERE}

The upper limits $U L_{j}=L L_{j+1}(j=1,2,3,4)$ of thresholds are 15, 28, 55, 75 thousand euros, being the first lower limit $L L_{1}=0$; tax rates $t_{j}$ range between 23 and 43 percent. By applying the rate schedule to the tax base the gross tax liability $G T_{i}$ is obtained.

In order to determine the net tax liability $T_{i}$, tax law admits three distinct kinds of effective tax credits. They are: tax credits for earned income $c_{i}^{1}\left(x_{i}^{M R}\right)$; tax credits for dependent individuals within the household $c_{i}^{2}\left(x_{i}^{M R}\right)$; tax credits for items of expenditure $c_{i}^{3}$. The net tax liability $T_{i}$ is then evaluated as:

$$
T_{i}= \begin{cases}G T_{i}-c_{i}^{1}\left(x_{i}^{M R}\right)-c_{i}^{2}\left(x_{i}^{M R}\right)-c_{i}^{3} & \text { if } \quad G T_{i}>c_{i}^{1}\left(x_{i}^{M R}\right)+c_{i}^{2}\left(x_{i}^{M R}\right)+c_{i}^{3} \\ 0 & \text { if } \quad G T_{i} \leq c_{i}^{1}\left(x_{i}^{M R}\right)+c_{i}^{2}\left(x_{i}^{M R}\right)+c_{i}^{3}\end{cases}
$$

where $x_{i}^{M R}=x_{i}-d_{i}^{1}$.

In what follows we do not consider regional and municipal surtaxes and then we evaluate taxpayer $i$ 's net income as $z_{i}=x_{i}-T_{i}$. 
Focusing on tax credits for employees and pensioners as well as self-employed,

$$
C_{i}^{1}\left(x_{i}^{M R}\right)= \begin{cases}t_{1} m_{r} & \text { if } x_{i}^{M R} \leq m_{r} \\ \left(t_{1} m_{r}-a_{r}\right)+a_{r}\left(\frac{L L_{2}-x_{i}^{M R}}{L L_{2}-m_{r}}\right) & \text { if } m_{r}<x_{i}^{M R} \leq L L_{2} \\ \left(t_{1} m_{r}-a_{r}\right)\left(\frac{L L_{4}-x_{i}^{M R}}{L L_{4}-L L_{2}}\right)+b & \text { if } L L_{2}<x_{i}^{M R} \leq L L_{4} \\ 0 & \text { if } x_{i}^{M R}>L L_{4}\end{cases}
$$

where $t_{1}$ is the lowest marginal tax rate (23 percent); $m_{r}$ with $r=(1,2,3,4)$ (the level of $x_{i}^{M R}$ below which taxpayer has a nil net tax liability) is equal to 8,000 euros for employees $\left(m_{1}\right)$, 7,500 for pensioners younger than $75\left(m_{2}\right)$, 7,750 for pensioners older than $75\left(m_{3}\right), 4,800$ for the self-employed $\left(m_{4}\right)$, and zero for non-working taxpayers; $a_{r}$ is equal to 502 euros for employees $\left(a_{1}\right)$, 470 for pensioners younger than $75\left(a_{2}\right)$, 486 for pensioners older than $75\left(a_{3}\right)$, zero for self-employed $\left(a_{4}\right)$; $b$, that ranges from 10 to 40 euros in the bandwidth 23-28 thousand euros, is applied only to employees (as discussed later, we always set $b=0$ in simulations). Non-working taxpayers have no tax credit for earned incomes. Finally, this tax credit decreases from zero to $m_{4}$, and from $m_{4}$ to $L L_{4}$ only for self-employed taxpayers.

Four different tax credits for type of relationship are allowed: tax credit for dependent children $c_{i}^{2 H}\left(x_{i}^{M R}\right)$, further tax credit for households with more than three children $c_{i}^{2 H F}$, tax credit for dependent spouse $c_{i}^{2 S}\left(x_{i}^{M R}\right)$, and tax credit for other household components $c_{i}^{2 O}\left(x_{i}^{M R}\right)$. The overall value for $c_{i}^{2}\left(x_{i}^{M R}\right)$ is then $c_{i}^{2}\left(x_{i}^{M R}\right)=c_{i}^{2 H}\left(x_{i}^{M R}\right)+c_{i}^{2 H F}+c_{i}^{2 S}\left(x_{i}^{M R}\right)+c_{i}^{2 O}\left(x_{i}^{M R}\right)$. In particular,

$$
c_{i}^{2 H}\left(x_{i}^{M R}\right)= \begin{cases}c_{i}^{2 H p} \frac{q+(f-1) e-x_{i}^{M R}}{q+(f-1) e} & \text { if } 0<x_{i}^{M R} \leq q+(f-1) e \\ 0 & \text { if } x_{i}^{M R}>q+(f-1) e\end{cases}
$$

where $f=\sum_{l=1}^{4} f_{l}$ is the overall number of dependent children; $f_{1}$ is the number of dependent children older than 3 years if the dependent children within the household are 3 or less; $f_{2}$ is the number of dependent children younger than 3 years if the dependent 
children within the household are 3 or less; $f_{3}$ is the number of dependent children older than 3 years if the dependent children within the household are more than $3 ; f_{4}$ is the number of dependent children younger than 3 years if the dependent children within the household are more than 3 ; $e$ is equal to 15,000 euros; $q$ is equal to 95,000 ; $c_{i}^{2 H p}=\sum_{l=1}^{4} f_{l} c_{i}^{2 H p l}$; the present values for the potential tax credits are: $c_{i}^{2 H p 1}=800$, $c_{i}^{2 H p 2}=900, c_{i}^{2 H p 3}=1,000, c_{i}^{2 H p 4}=1,100$ euros.

Moreover, whenever $c_{i}^{2 H}\left(x_{i}^{M R}\right)>0$ and the dependent children within the households are more than 3 the tax law admits a further tax credit $c_{i}^{2 H F}$ equal to 1,200 euros for all beneficiaries. The tax credits for dependent children have to be split between spouses whenever both of them have a positive gross income. Finally,

$$
c_{i}^{2 S}\left(x_{i}^{M R}\right)= \begin{cases}c_{i}^{2 S p}-u \frac{x_{i}^{M R}}{L L_{2}} & \text { if } x_{i}^{M R} \leq L L_{2} \\ c_{i}^{2 S p}-u & \text { if } L L_{2}<x_{i}^{M R} \leq w \\ \left(c_{i}^{2 S p}-u\right) \frac{k-x_{i}^{M R}}{k-w} & \text { if } w<x_{i}^{M R} \leq k \\ 0 & \text { if } x_{i}^{M R}>k\end{cases}
$$

and

$$
c_{i}^{2 O}\left(x_{i}^{M R}\right)= \begin{cases}c_{i}^{2 O p} \frac{k-x_{i}^{M R}}{k} & \text { if } x_{i}^{M R} \leq k \\ 0 & \text { if } x_{i}^{M R}>k\end{cases}
$$

where $u$ is equal to 110 euros, $w$ is equal to 40 thousand euros, $k$ is equal to 80 thousand euros, $c_{i}^{2 S p}$ is equal to 800 euros and $c_{i}^{2 O p}$ is equal to 750 euros. The present tax code considers higher values than $c_{i}^{2 S p}-u$ in the income range 29,000-35,200 euros. Instead of 690 euros, in this income range values ranging from 700 to 720 euros are applied. We do not consider these differences in simulations, always letting $c_{i}^{2 S p}-u$ be equal to 690 euros.

Tax credits for items of expenditures $c_{i}^{3}$ can be classified in two groups according to the percentage of the expense the tax law admits as a tax credit. There are expenses that 
allow a tax credit of 19 percent and 36 percent, respectively. ${ }^{2}$ The 19 percent tax credits (we label this variable expenditure 1) are very large, 19 different cases, such as expenses for health care, mortgage interests, etc.; 36 percent tax credits (expenditure 2) are allowed for home restructuring-related expenses. All together, tax law admits 30 different tax credits for items of expenditure. Finally, tax law admits a tax credit for tenants; it is 300 euros if $x_{i} \leq 15,494$ (we label this variable tenants 1); 150 if $15,494<x_{i} \leq 30,987$ (tenants 2); 992 euros if $x_{i} \leq 15,494$ and if the taxpayers are younger than 30 (tenants 3).

\section{Distribution of Income and Personal Income Tax Progressivity}

Let $x_{1}, x_{2}, \ldots, x_{n}$ be the pre-tax income levels associated to $n$ income units. The corresponding post-tax income levels and tax levels are $z_{1}, z_{2}, \ldots, z_{n}$ and $T_{1}, T_{2}, \ldots, T_{n}$, respectively. We denote the pre-tax and the post-tax income distribution as well as the tax distribution by $X, Z$ and $T$, respectively.

As is well known, inequality among pre- and post-tax income levels as well as tax levels can be evaluated by the Gini coefficient. Let $G_{X}, G_{Z}$ and $G_{T}$ be the corresponding Gini coefficient for pre-tax income, post-tax incomes and taxes, respectively. Then,

$$
G_{\varepsilon}=\frac{2 \operatorname{cov}[\varepsilon, F(\varepsilon)]}{\mu_{\varepsilon}}
$$

where $\varepsilon=X, Z, T, \mu_{\varepsilon}$ is the average value for pre-tax and post-tax incomes and taxes, $\operatorname{cov}$ represents the covariance and $F(\varepsilon)$ is the cumulative distribution function.

Given a progressive taxation, it is not guaranteed that post-tax ordering be equal to the pre-tax income one. Indeed, it is most likely that these two orderings differ because of the re-ranking due to the progressive taxation. Therefore, the inequality of $Z$ and $T$ can be evaluated once these distributions are ordered according to the corresponding pre-tax incomes, ranked in a non-decreasing order. For what concerns post-tax incomes and taxes, the corresponding concentration coefficient can then be evaluated as follows:

\footnotetext{
2 The tax code considers also a 55 percent tax credit for interventions for energy saving and a 20 percent tax credit for purchasing of a washing machine. Because of the low number of taxpayers interested in these two kinds of tax credits, we did not considered them in the microsimulation model.
} 
$C_{\varepsilon}=\frac{2 \operatorname{cov}[\varepsilon, F(X)]}{\mu_{\varepsilon}}$

Progressive taxation produces two different effects on the distribution of pre-tax incomes: post-tax income inequality is lower than that measured on pre-tax income distribution, whilst tax inequality is greater. The first effect is known as the redistributive effect of the tax and the second one as departure from proportionality of the progressive taxation (Lambert, 2001). The overall redistributive effect of the tax $R E$ can be evaluated as

$R E=G_{X}-G_{Z}=\left(G_{X}-C_{Z}\right)-\left(G_{Z}-C_{Z}\right)=R S-R^{A P K}$

where $R S=G_{X}-C_{Z}$ is the Reynolds-Smolensky index, whilst $R^{A P K}=G_{Z}-C_{Z}$ is the Atkinson-Plotnik-Kakwani index. The more the tax is progressive, the greater $R E$ and $R S$; the more the tax causes re-ranking, the greater the negative contribution of reranking to the overall redistributive effect. Note that if the tax does not cause re-ranking $\left(R^{A P K}=0\right)$, then $R E=R S$.

The departure from proportionality of the progressive taxation can instead be evaluated by the Kakwani index $K=C_{T}-G_{X}$. The Kakwani and the Reynolds-Smolensky indexes are linked by the overall average tax rate $\theta$, namely

$$
\theta=\frac{\sum_{i=1}^{n} T_{i}}{\sum_{i=1}^{n} x_{i}}
$$

As a consequence, $R S=\frac{\theta}{1-\theta} K$. This formula tell us that the Reynolds-Smolensky index has two determinants: the overall average tax rate and the Kakwani index.

In what follows we focus only on the Reynolds-Smolensky index and then we are interested in finding the best tax structure able to determine a given tax revenue (smaller than the present one) and to yield to the greatest $R S$ while getting no loser taxpayers.

Since we impose a reduction of the tax revenue, note that the value of $\theta$ will be smaller than the present one. Note also that the simulated $K$ will be greater than the present one in order for $R S$ to be the highest. 


\section{The Data and the Static Microsimulation Model}

The microsimulation model used in this work estimated the most important taxes and contributions characterizing the Italian fiscal system. Here we employ the microsimulation model module concerning the personal income tax (hereafter PIT). It considers as input data those provided by the Bank of Italy in its 2012 Survey on Households Income and Wealth (hereafter BI-SHIW). The Survey contains information on household income and wealth in the year 2010, covering 7,951 households and 19,836 individuals (Bank of Italy, 2012). The sample is representative of the Italian population, composed of about 24 million households and 60 million individuals.

The SHIW-BI provides information only on each individual's disposable income, which considers items of incomes that are taxed within the PIT or that can be exempt from the tax as well as can be taxed under a separate regime. Therefore, the microsimulation model first distinguishes all incomes included in the PIT taxable income definition, incomes exempt from any taxes and incomes taxed under a separate regime. Then the PIT gross income distribution is evaluated starting from the PIT net income distribution. The transition from the post- to the pre-tax personal income of each individual has been computed by applying the algorithm proposed by Immervoll and O’Donoghue (2001). Using original sample weights, the grossing-up procedure simply proportions the sum of individuals' sample weights to the dimension of the population as estimated by the National Statistical Office (ISTAT). Then the grossed-up number of PIT taxpayers has been obtained by considering individuals with a positive gross income within the microsimulation model, 13,791 taxpayers within the sample, corresponding to about 40 million taxpayers in the population.

Considering the income units, results concerning the PIT gross income distribution are very close to the Ministry of Finance (2011) official statistics both considering the composition of PIT income units by work status as well as by their mean gross income and the gross income distribution by income classes. In addition, also the overall tax revenue resulting from the microsimulation model (148.75 billion euros) is very close to that showed in the official statistics.

Considering all individual taxpayers, Figure 1 compares the frequency density function obtained with the microsimulation model and the one obtained using the Ministry of 
Finance official data by income classes. Similar pictures emerge considering the frequency density function for pensioners and employees, who represent about 85 percent of all taxpayers.

\section{FIGURE 1 AROUND HERE}

Table 2 shows the inequality indices for individual taxpayers, which is our reference situation for the Reynolds-Smolensky index maximization. The Gini coefficient for the gross income distribution is 0.4433803 , whilst that for the net income distribution is 0.3913966. The overall redistributive effect $R E$ is 0.0519837. The concentration coefficient for the net income distribution is 0.3907739, whist that on the net tax liability distribution is 0.6721563 ; therefore, the Reynolds-Smolensky $R S$ index is equal to 0.0526064 and the Kakwani index is 0.2287760 . The overall average tax rate is 0.1869570 , whilst the Atkinson-Plotnick-Kakwani $R^{A P K}$ index is equal to 0.0006227 .

\section{TABLE 2 AROUND HERE}

\section{Genetic Algorithm}

\subsection{General Overview}

Genetic algorithms (henceforth GAs) are a search heuristic which belong to the field of evolutionary algorithms, a subfield of artificial intelligence. Since their inception (Holland, 1975), GAs found a wealth of applications in the most varied research disciplines, beyond computational science, mathematics, physics, bioinformatics, etc.. Applications in economics also exist, broadly including game theory, finance related works, schedule optimization, and whenever some sort of learning mechanism is needed; historically, the first attempt at employing GAs in economics is due to Miller (1986) research on adaptive behavior.

To our knowledge, no previous attempts at employing GAs for tax systems optimization exist, to date. 
The huge solutions search space, which is the aftermath of the combinatorial effect of truly many parameters, poses a serious challenge to traditional optimization techniques; brute force methods are out of question, just like iterative methods (cfr. Newton's); GAs appear an obviously appropriate choice.

Candidate solutions, which in the GA are internally represented as 'genomes', vectors of real numbers ${ }^{3}$, are generated as an initial 'population' at random. Evolutionary operators iteratively select, cross-breed and mutate the best (most 'fit', according to an objective function called 'fitness function') individuals in order to produce an offspring of individuals - the subsequent 'generation' - that will enter a new reproduction step. The individuals' average fitness increases after every generation, until a satisfactory solution is found. The stopping criterion normally employed is related to the population homogeneity: as the search process becomes closer to an optimum, the individuals become more and more similar among them.

The GA implementation employed in this work is based on Python's open-source Pyevolve library (Perone, 2009); the population selection mechanism across generations is the standard roulette wheel (fitness proportional), while the evolutionary crossover operator is a standard one-point. A low mutation rate value and a high crossover rate have also been utilized, in order to let the search process converging reasonably quick on solutions, while maintaining the ability to escape local minima.

The population size vs. number of generations trade-off has been tackled and solved favouring numerous populations vs. fewer evolutionary steps.

Detailing the trimming of the GAs technical parameters is out of the scope of this work; suffice to say, as agreed upon by a vast literature, it is an ad-hoc process, to be performed mostly by trial and error, on every specific search domain.

\subsection{The Structure of the Genetic Algorithm We Employ}

As the starting point, we let the GA set a population of 500 different tax structures and then we let it evolve them for 1,500 generations. Consequently, the GA has to evaluate as much as 0,75 million candidate solutions, applying different tax structures to the

\footnotetext{
${ }^{3}$ In the early GA implementations (BCGA, binary-coded genetic algorithms), the solutions space had to be coded in binary numbers; RCGA, real-coded genetic algorithms, allow working with variables in continuous domains; cfr. Herrera et al. (1998).
} 
same pre-tax income distribution composed of 13,791 taxpayers. We set the crossover rate equal to 0.8 and the mutation rate equal to 0.025 .

For each tax structure and for each taxpayer, the GA computes all the relevant tax variables in the transition from the pre- to the post-tax income. For each tax structure it then computes the overall tax revenue, the share of loser taxpayers by considering each taxpayer's actual net tax liability, the average loss for the loser taxpayers as well as the Reynolds-Smolensky $R S$ index (the four parts of the objective fitness function to maximize, see below), and saves all these resulting values, in addition to all parameters of the tax, on a dump file.

We employ a computer powerful enough to evaluate 0,75 million runs in about 3 days; the duration of our average run is then 0.3 seconds.

The GA has to maximize a fitness function. We employed

fitness $=\alpha R S-\beta \Delta-\delta \Pi-\lambda \Omega$

where $\Delta$ is the ratio between the absolute deviation of the computed tax revenue of each run from the target one (138.25 billion euros, 10.5 billion euros less than the present tax revenue) and the target tax revenue, whilst $\Pi$ is the share of taxpayers losing with the simulated tax structure, $\Omega$ is the average loss (in euros) for the loser taxpayers, $\alpha, \beta, \delta$ and $\lambda$ are all positive parameters. We fix $\alpha=18, \beta=1.4, \delta=1$ and $\lambda=3,000^{-1}$. We made several attempts, with different parameters, and this combination of parameters seems to be the most promising one.

The first term on the RHS of Equation (11) shows the part of the fitness function depending on $R S$. We highly favour $R S$ with respect to $\Delta, \Pi$, and $\Omega$, since we are interested in obtaining the highest Reynolds-Smolensky index. The second and the third as well as the fourth terms on the RHS of the fitness function show the 'penalties' we impose to the fitness value when $\Delta, \Pi$ and $\Omega$ became too large. As a result, the smaller $\Delta, \Pi$ and $\Omega$, the more the fitness value increases.

When the GA has evolved for a reasonable number of generations, we obtain $\Delta \approx 0$, $\Pi \approx 0$, the smallest $\Omega$, and the highest $R S$. We then can observe the parameters of the 'best' structure of the tax.

Each tax structure is characterized by 33 different parameters (see Table 3), each of them related to a specific parameter of the Italian PIT structure described in Section 2. 
In order to evaluate each of the 33 parameters, the GA couples 36 'chromosomes' that are values ranging from zero to 1 .

We now turn to describe how we let the GA trim each 'chromosome'.

First of all, we let the GA choose five marginal tax rates as in the actual tax code. Given the constraints we impose, we know that the first marginal tax rate cannot be too much lower than the present one; conversely we know that the highest marginal tax rate cannot be too much higher than the present one (since we impose a 'no loser' taxpayers constraint). We set the lowest marginal tax rate not to be lower than 15 percent (being the present value equal to 23 percent), and the highest marginal tax rate not be greater than 43 percent (being the present value equal to 43 percent).

In particular, the GA randomly sets a group of six chromosomes serving for the definition of the five marginal tax rates. It then adds them up in order to obtain a normalization value as follows: norm $_{t}=\frac{0.43-0.15}{\sum_{\varphi=1}^{6} \text { chromosome }_{\varphi}}$.

The GA finally choose the five tax rates $t_{\lambda}$ with $\lambda=(1,2,3,4,5)$ as follows:

$t_{\lambda}=0.15+\sum_{\varphi=1}^{\lambda}$ chromosome $_{\varphi} *$ norm $_{t}$

We then set a second group of 5 chromosomes (7-11) defining the four upper limits $U L_{j}=L L_{j+1}$ of all thresholds, being $L L_{1}=0$ by definition and $U L_{j}<U L_{j+1}$. We applied an empirical strategy similar to that employed for the definition of the marginal tax rates and we impose $U L_{1} \geq 15,000$ (being the present value equal to 15 thousand euros) and we let the highest value of $U L_{4}$ be 75 thousand euros (as in the present tax code). As a consequence,

$$
\text { norm }_{U L}=\frac{75,000-15,000}{\sum_{\varphi=7}^{11} \text { chromosome }_{\varphi}}
$$

and, for $j=1,2,3,4$,

$$
U L_{j}=15,000+\sum_{\varphi=1}^{j} \text { chromosome }{ }_{\varphi}^{*} \text { norm }_{U L}
$$


Afterwards we define 25 chromosomes related to the tax credits structure. Starting from the tax credit for employees (Equation (3)), we let the GA choose the no tax area $m_{1}$ applied to employees, that is the limit of pre-tax income below which these taxpayers face a zero net tax liability, between 8 thousand euros (the present value) and $0.8 * U L_{1}$ (being $\frac{m_{1}}{U L_{1}}=\frac{8,000}{15,000}=0.5 \overline{3}$ according to the present tax structure): $m_{1}=8,000+$ chromosome $_{12} *\left(0.8 * U L_{1}-8,000\right)$. As a consequence, we let $m_{1}$ be greater than the present value (but not too much: note that the higher $\frac{m_{1}}{U L_{1}}$, the higher the effective marginal tax rate the taxpayers belonging to the income bandwidth $\left(m_{1} ; U L_{1}\right)$ have to face). There is a specific reason for this choice: ceteris paribus, having to maximize the Reynolds-Smolensky index given a revenue constraint, the larger the share of taxpayers with a nil net tax liability, the higher the ReynoldsSmolensky index (and the higher the tax rates and narrower the upper limit of each threshold in order to obtain the target tax revenue). The constraint we impose on the share of loser taxpayers lets the GA chose the highest admissible value for $m_{1}$.

The GA then choose $m_{2}, m_{3}, m_{4}$ as follows:

$$
\begin{aligned}
& m_{2}=\left(0.9375 * m_{1}\right)-\left(\text { chromosome }_{13} * 0.25 * 0.9375 * m_{1}\right) \\
& m_{3}=m_{2}+\text { chromosome }_{14} *\left(0.96875 * m_{1}-m_{2}\right) \\
& m_{4}=0.6 * m_{1}-\text { chromosome }_{15} * 0.6 m_{1}
\end{aligned}
$$

where 0.25 is arbitrarily chosen, whilst $0.9375=\frac{m_{2}}{m_{1}}, 0.96875=\frac{m_{3}}{m_{1}}$, and $0.6=\frac{m_{4}}{m_{1}}$ according to the present values. In so doing we let the GA choose $m_{r}$ with $r=(1,2,3,4)$ in a large combinatorial space preserving the present rank of $m_{r}$.

Looking at Equation (3), besides parameters $m_{r}$, the effective tax credit $c_{i}^{1}\left(x_{i}^{M R}\right)$ is piecewise linearly decreasing with respect to two lower limits of thresholds defined in Table 1: from $m_{r}$ to $L L_{2}$, and from $L L_{2}$ to $L L_{4}$, being $c_{i}^{1}\left(x_{i}^{M R}\right)=0$ if $x_{i}^{M R}>L L_{4}$. For a very important reason we do not change this structure of the tax credit, that is we do not let this tax credit be piecewise decreasing with respect to limits others than $L L_{2}$ and $L L_{4}$. If $c_{i}^{1}\left(x_{i}^{M R}\right)$ were piecewise decreasing with respect to other thresholds, the number 
and the level of the effective marginal tax rates were not under control, leading to unpleasant and inefficient outcomes. Having the GA chosen $t_{1}$ and $m_{r}$, note that the potential tax credits $t_{1} m_{r}$ are automatically defined. We then let the GA choose also the parameters $a_{r} r=(1,2,3)$ in the range $\left(0-t_{1} m_{r}\right)$ by defining chromosomes 16,17 , and 18 (as described in Section 2, parameter $a_{4}$ is equal to zero and we keep it unchanged). In so doing, a very large combination of tax credits for earned incomes is allowable. All these combinations are a continuous and non-increasing function with respect to $x_{i}^{M R}$. Finally, we always set the parameter $b$ equal to zero. At present it is applied only to employees and its values range from 10 to 40 euros for levels of $x_{i}^{M R}$ belonging to the threshold 23-28 thousand euros. We prefer this parameter fixed to zero since if it were positive, it would not let the tax credit under discussion be a continuous function for all levels of $x_{i}^{M R}$.

Similarly, we then define specific chromosomes to set the combinatory space for the three tax credits for dependent individuals within the household: $c_{i}^{2 H}\left(x_{i}^{M R}\right), c_{i}^{2 S}\left(x_{i}^{M R}\right)$ and $c_{i}^{2 O}\left(x_{i}^{M R}\right)$.

Starting with the tax credits for dependent children $c_{i}^{2 H}\left(x_{i}^{M R}\right)$, we let the GA choose the potential level of the tax credits $c_{i}^{2 H p l}$ in the range 500-4,000 euros (being the present values ranging between 800 and 1,100 euros). Similar to the choice of the tax rates and the upper limits of the thresholds, we then define 5 different chromosomes (from 19 to 23) to set the 4 kinds of tax credits for dependent children. In so doing, we set specific constraints in order to let the potential tax credit be higher for households with more than 3 children and lower for those with less than 3 children as well as higher for child aged 3 or less and lower for a child aged more than 3. Then we introduce chromosomes 24 and 25 for the choice of parameters $q$ and $e$. We let the GA choose $q$ between zero and 95 thousand euros (being the present value equal to 95 thousand), and the parameter $e$ between zero and 15 thousand euros (being the present value equal to 15 thousand). Note that these are very large ranges, so that the GA can choose an extremely large set of combinations. Finally, the GA chooses chromosome 26 in order to set $c_{i}^{2 H F}$ between zero and 4 thousand euros (being the actual value 1,200 euros). 
Turning to the effective tax credit for the spouse $c_{i}^{2 S}\left(x_{i}^{M R}\right)$, we generate chromosome 27 in order for $c_{i}^{2 S p}$ to range between 500 and 2,500 thousand euros (being the present value equal to 800 euros), and a further chromosome 28 in order for the parameter $u$ to range between zero and $c_{i}^{2 S p}$. Chromosomes 27 and 28 let the effective tax credit for the spouse to be a non-increasing function with respect to $x_{i}^{M R}$ and let the GA choose among a very large combination of structures for this tax credit.

Looking at Equation (5), this effective tax credit $c_{i}^{2 S}\left(x_{i}^{M R}\right)$ is piecewise linearly decreasing with respect to three thresholds: from zero to $L L_{2}$, from $L L_{2}$ to $L L_{3}<w<L L_{4}$, and from $w$ to $k>L L_{5}$. In order to define $w$ and $k$, we introduced chromosomes 29 and 30 as follows:

$w=L L_{2}+$ chromosome $_{29} *\left(L L_{4}-L L_{2}\right)$

$k=w+$ chromosome $_{30} *(80,000-w)$

Finally, concerning the tax credit for other dependent individuals within the household, we introduce chromosome 31 in order for $c_{i}^{2 O p}$ to range between zero and $c_{i}^{2 H p 1}$, and we impose $c_{i}^{2 O}\left(x_{i}^{M R}\right)$ to be linearly decreasing between zero and $k$, and to be zero if $x_{i}^{M R}>k$.

Afterwards, we let the GA choose chromosomes 32, 33 and 34 in order to set tax credits for tenants:

$$
\begin{aligned}
& \text { tenants }_{1}=\text { chromosome }_{32} * 2,000 \\
& \text { tenants }_{2}=\text { chromosome }_{33} * \text { tenants }_{1} \\
& \text { tenants }_{3}=\text { tenants }_{1}+\text { chromosome }_{34} * 2,000
\end{aligned}
$$

According to the present tax code, these tax credits are applied to two income thresholds: 15,494 and 30,987 euros; we consider this aspect by letting them change according to $U L_{1}$ and $U L_{2}$.

Finally, the GA chooses chromosomes 35 and 36 in order to set the percentage (at present equal to 0.19 and 0.36 ) of the expenses the tax law admits as further tax credits for items of expenditure. 


\section{Results}

Table 3 shows all the parameters of the 'best' tax structure able to maximize the Reynolds-Smolensky index, given that the tax revenue is 10.5 billion euros lower than the present one, and almost no taxpayers have to be worse off due to the tax reform. As can be noted, the bottom marginal tax rate $t_{1}$ significantly decreases from 23 to 21.91 percent; this reduction lowers the gross tax liability, not only for the poorest taxpayers but also for all the other taxpayers. Also the other marginal tax rates, with the exception of the second one $t_{2}$ (which increases to 28.82 percent), decrease: $t_{3}$ from 38 to 35.74 percent, $t_{4}$ from 41 to 39.83 percent, and $t_{5}$ from 43 to 42.99 percent. In terms of the bandwidth of the thresholds, the first one broadens from $0-15,000$ to $0-18,041$ euros, whilst the second, the third and the fourth ones narrow from 15,000-28,000 to 18,04128,336 euros, from 28,000-55,000 to 28,336-43,891 euros, and from 55,000-75,000 to $43,891-59,446$ euros, respectively; finally, the top marginal tax rate is applied to incomes above 59,446 euro instead of 75,000 euros.

\section{TABLE 3 AROUND HERE}

The 'no tax' area enlarges for all the four kinds of taxpayer: $m_{1}$ increases from 8,000 to 12,684 euros, $m_{2}$ from 7,500 to $11,122, m_{3}$ from 7,750 to 12,288 , whilst $m_{4}$ rises from 4,800 to 7,610. Note that $\frac{m_{r}}{U L_{1}}$ also increases. In particular, the GA does not choose the maximum values we imposed: $\frac{m_{1}}{U L_{1}}=0.70 ; \frac{m_{2}}{U L_{1}}=0.62 ; \frac{m_{3}}{U L_{1}}=0.68$.

The parameters defining the shape of the effective tax credits for earned income $c_{i}^{1}\left(x_{i}^{M R}\right)$ increase considerably: $a_{1}$ from 502 to 1,522 euro, $a_{2}$ from 470 to 1,299 , and $a_{3}$ from 486 to 1,499 euros.

Since we impose the tax credit $c_{i}^{1}\left(x_{i}^{M R}\right)$ that is piecewise decreasing with respect to $L L_{2}$ and $L L_{4}$, note also that after the tax reform it is positive up to 43,891 euros instead of 55,000. As an example, Figure 2 compares the effective tax credits for employees before and after the tax reform. Note that after the tax reform the slope of the effective 
tax credit is higher (in absolute value) in terms of both the income ranges $\left(m_{1}-U L_{1}\right)$ and $\left(U L_{1}-U L_{3}\right)$. This shape also affects the effective marginal tax rates, which increases with respect to the ones obtained with the present tax structure. Therefore, a trade-off of equity-efficiency emerges: in order for the Reynolds-Smolensky index to be the highest, we have to agree to higher effective marginal tax rates.

\section{FIGURE 2 AROUND HERE}

The shape of the tax credit for a spouse $c_{i}^{2 S}\left(x_{i}^{M R}\right)$ is very similar to the present one (Figure 3). The potential tax credit is a little bit higher than before, and the effective one is flat in the income range 0-25,740 euros; it becomes zero above 78,143 euros.

In terms of the tax credits for dependent children, even if the potential tax credit $c_{i}^{2 H p 1}$ is slightly lower than that applied by the present tax structure (769 euros against 800), the other three potential tax credits are significantly higher: $c_{i}^{2 H p 2}$ increases from 900 to 1,846 , $c_{i}^{2 H p 3}$ increases from 1,000 to 1,846 , whilst $c_{i}^{2 H p 4}$ increases from 1,100 to 2,923 euros.

\section{FIGURE 3 AROUND HERE}

Note also that since $c_{i}^{2 H p 3}$ and $c_{i}^{2 H p 4}$ are so much higher than before, $c_{i}^{2 H F}$ can be set equal to zero. The income limits above which this tax credit become zero are unchanged: $q$ is equal to 95,000 , whilst $e$ is equal to 15,000 . A similar picture emerges when considering the tax credit for other dependent individual within a household: the potential tax credit is a little bit higher than the present value, and is positive for income below 78,143 euros instead of 80,000.

Focusing on the remaining parameters of the tax, the tax credit for tenants are always higher: the one for tenants with gross income below $U L_{1}$ is double than the present value (637 euros against 300); the tax credit for tenants with income in the range $\left(U L_{1}-U L_{2}\right)$ is 283 euros against 150; Also the tax credit for younger tenants is higher (1,206 euros instead of 992). 
Finally, the percentages of expenses the tax law admits as a tax credit also remains relatively unchanged: 18.87 percent instead of 19 percent, and 42.40 percent instead of 36 percent.

Very few taxpayers are worse off as a result of this tax reform (0.9 percent), whilst 24.6 percent are unaffected (we consider as unaffected the taxpayers for whom the absolute value of the computed net tax liability differs from the present one by, at most, one euro). The remaining 74.5 percent of taxpayers gain from the reform. Looking at the composition of the tax cut in terms of income classes (Table 4), 89.3 percent of the tax cut favours taxpayers in the income range 8-28 thousands euro, whilst 1.9 percent favours taxpayers with lower incomes. This is due to the fact that the Italian personal income tax system does not admit a negative income taxation; therefore, taxpayers with a nil net tax liability (almost all taxpayers with income lower than 8 thousand euros) are not affected by the tax reform. If the Italian PIT allowed negative income taxation, the tax reform would show a different distribution in terms of the tax cut among income classes: in particular, there would be lower gains for the top income earners and higher gains for the bottom ones.

\section{TABLE 4 AROUND HERE}

Only 5.7 percent of the tax cut favours taxpayers with incomes in the range 28-55 thousands euro, whilst the remaining 3 percent favours richer taxpayers. It can be observed that the RS could be higher, were the gains of the richer taxpayer transferred to the poorest ones. Given the structure of chromosomes described in sub-section 5.2, this is not possible, or at most, not likely, since the GA has to balance the effects on $R S, \Delta$ and $\Pi$ due to 33 parameters.

Finally, Table 5 compares the inequality indexes for taxpayers according to the present tax structure, and those obtained by applying the new structure of the tax to the same pre-tax income distribution. As can be noted, $R S$ is 10.3 percent higher than the present value: since the overall average tax rate decreases from 18.7 percent to 17.4 percent, the Kakwani index increases by 20.5 percent. Note also that this tax reform positively affects the $R^{A P K}$ index, which is 4.2 percent lower. 


\section{TABLE 5 AROUND HERE}

\section{Concluding Remarks}

In this paper we propose a new methodology to implement a personal income tax reform. In particular, given a settled tax cut decided by the Government (note that a similar strategy can be applied if the tax revenue increases), we show how a genetic algorithm can be employed in order to find out the values of all parameters defining the structure of the personal income tax able to satisfy a specific target. As an example, in this work our target is the maximization of the redistributive effect of the tax, while preventing almost all taxpayers being worse off with respect to the present tax structure. Our methodology can be applied to any other specific target.

We apply this methodology to the Italian personal income taxation system for two reasons: the tax structure is quite complicated, and recently the Government decided to reduce tax revenue by about 10.5 billion euro starting from 2015. The aim of this tax cut is to increase the purchasing power of households, and the tool is the introduction of a money transfer (not related to the structure of the personal income tax) only for employees with gross incomes in the range 8-26 thousand euros (in order for the yearly gain to be about one thousands euro), whilst all other kinds of taxpayer are not affected by this money transfer. Here we show that a better and more equity-oriented reform is possible: by reducing tax revenue by 10.5 billion euros, the redistributive effect of the tax increases by about 10 percent, whilst the Kakwani index increases by about 21 percent with respect to the corresponding values obtained applying the present structure of the tax. The gains are concentrated on taxpayers in the income range 8-28 thousand euros, since the Italian personal income tax system does not allow a negative income tax. The average gains are high: 659 euros in the income class 8-15 thousand euros, and 323 euros in the $15-28$ one. 


\section{References}

Bank of Italy (2012). Household Income and Wealth in 2010, Supplements to the Statistical Bulletin, XXII (New Series), No. 6.

Holland, J. H. (1992). Adaptation in Natural and Artificial Systems: an Introductory Analysis with Applications to Biology, Control, and Artificial Intelligence, MIT Press, Cambridge, MA; first edition (1975). University of Michigan Press, Ann Arbor, MI.

Herrera F., Lozano M. and Verdegay J.L. (1998). Tackling Real-Coded Genetic Algorithms: Operators and Tools for Behavioural Analysis, Artificial Intelligence Review, Vol. 12(4), pp. 265-319.

Immervoll, H. and O’Donoghue, C. (2001). Imputation of Gross Amounts from Net Incomes in Households Surveys. An application using EUROMOD, Working paper EM1, EUROMOD.

Lambert, P. J. (2001). The Distribution and Redistribution of Income, Third edition, Manchester University Press, Manchester and New York.

Miller, J. H. (1986). A Genetic Model of Adaptive Economic Behavior, University of Michigan Working Paper, Ann Arbor, MI.

Ministry of Finance, Department of Finance (2011). Statistical Reports.

Pellegrino, S., Piacenza, M. and Turati G. (2011). Developing a Static Microsimulation Model for the Analysis of Housing Taxation in Italy, The International Journal of Microsimulation, Vol. 4(2), pp. 73-85.

Perone, C. S. (2009). Pyevolve: a Python Open-Source Framework for Genetic Algorithms, ACM SIGEVOlution Newsletter, vol. 4, n. 1, pp. 12-20, ACM, New York. 
Figure 1: Frequency density function for all individual taxpayers

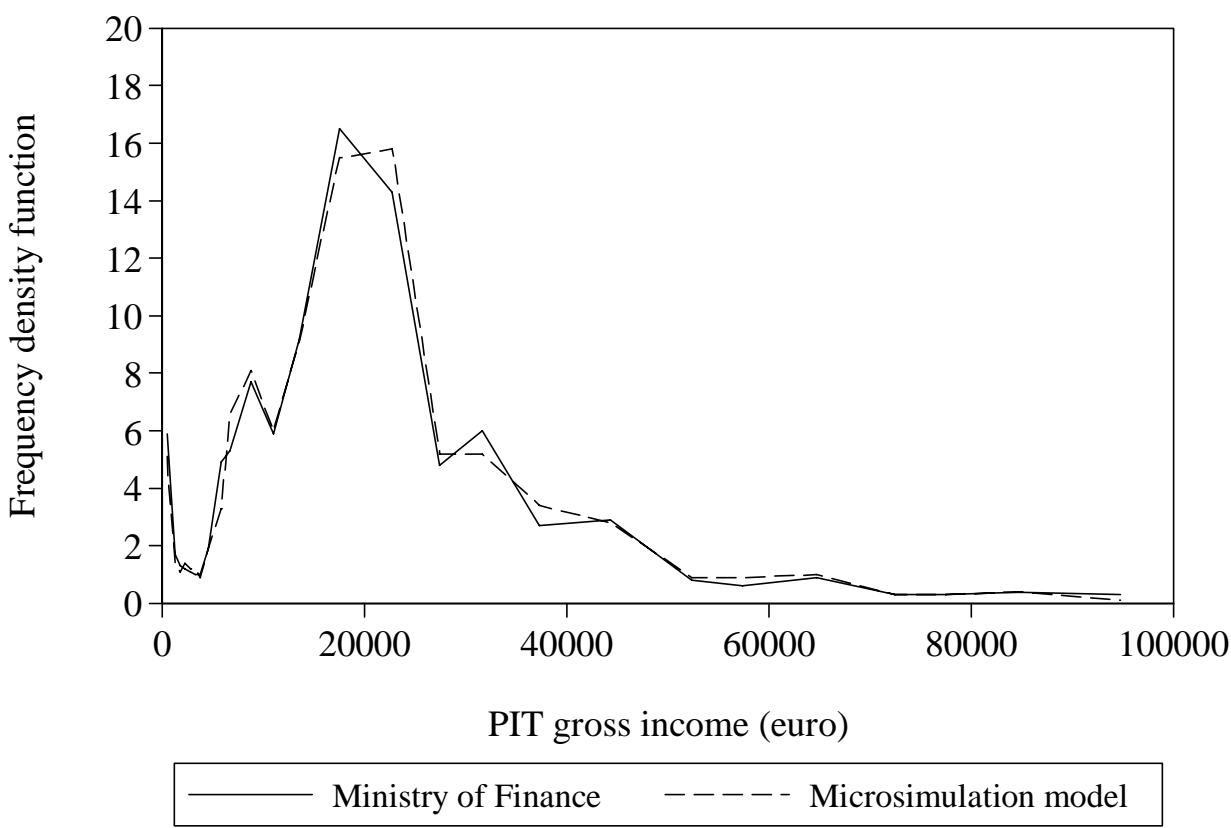

Figure 2: The effective tax credit for employees

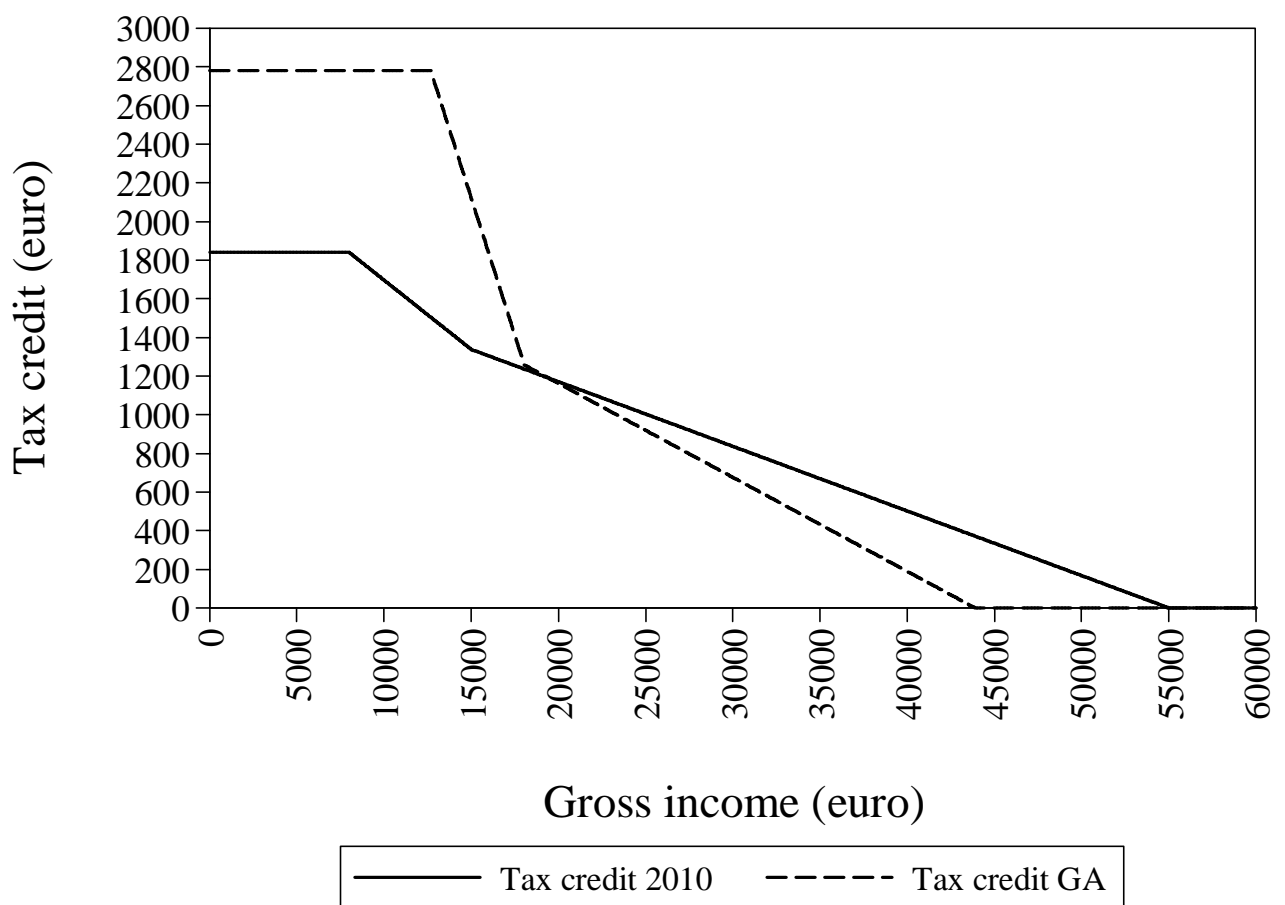


Figure 3: The effective tax credit for a spouse

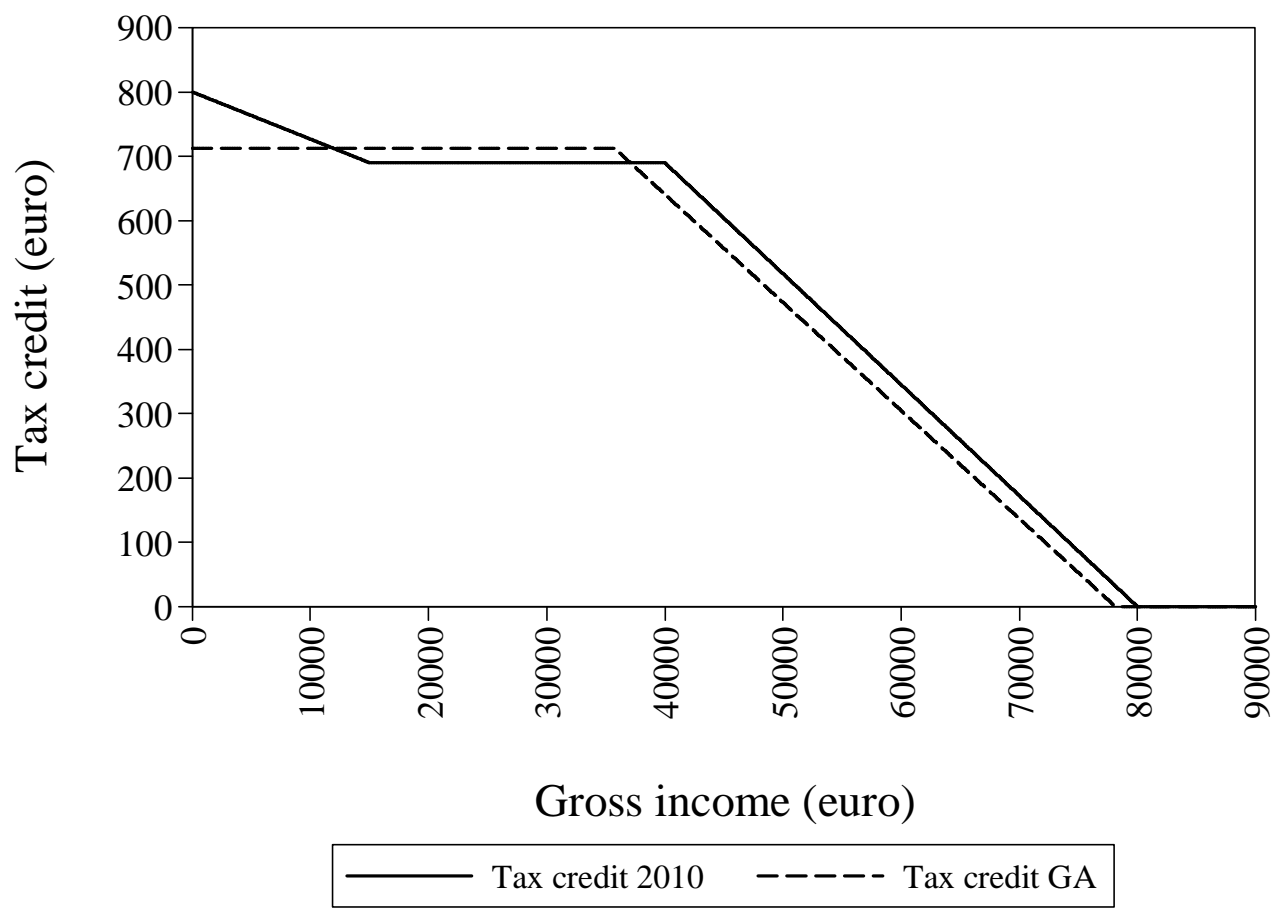


Table 1: Rate schedule

\section{Taxable income (euros)}

\begin{tabular}{cccc}
\hline \hline $\begin{array}{c}\text { Threshold } \\
(\boldsymbol{j})\end{array}$ & $\begin{array}{c}\text { Lower limit } \\
(\boldsymbol{L} \boldsymbol{L})\end{array}$ & $\begin{array}{c}\text { Upper limit } \\
(\boldsymbol{U} \boldsymbol{L})\end{array}$ & $\begin{array}{c}\text { Tax rate (\%) } \\
(\boldsymbol{t})\end{array}$ \\
\hline \hline 1 & 0 & 15,000 & 23 \\
\hline 2 & 15,000 & 28,000 & 27 \\
\hline 3 & 28,000 & 55,000 & 38 \\
\hline 4 & 55,000 & 75,000 & 41 \\
\hline 5 & 75,000 & - & 43 \\
\hline \hline
\end{tabular}

Source: Italian Tax Code.

Table 2: Inequality indexes for individual taxpayers

\begin{tabular}{lc}
\hline \hline \multicolumn{1}{c}{ Index } & Value \\
\hline \hline Gini coefficient for the gross income & 0.4433803 \\
\hline Gini coefficient for the net income & 0.3913966 \\
\hline Concentration coefficient for the net income & 0.3907739 \\
\hline Gini coefficient for the net tax liability & 0.6815444 \\
\hline Concentration coefficient for the net tax liability & 0.6721563 \\
\hline Redistributive effect & 0.0519837 \\
\hline Reynolds-Smolensky index & 0.0526064 \\
\hline Kakwani index & 0.2287760 \\
\hline Atkinson-Plotnik-Kakwani index & 0.0006227 \\
\hline Average tax rate & 0.1869570 \\
\hline \hline
\end{tabular}

Source: Own elaborations based on BI-SHIW. 
Table 3: Present and computed parameters of the tax

\begin{tabular}{|c|c|c|}
\hline Parameters & Present value & Best value \\
\hline$t_{1}$ & 0.23 & 0.2191237 \\
\hline$t_{2}$ & 0.27 & 0.2882474 \\
\hline$t_{3}$ & 0.38 & 0.3573711 \\
\hline$t_{4}$ & 0.41 & 0.3982787 \\
\hline$t_{5}$ & 0.43 & 0.4298956 \\
\hline$U L_{1}$ & 15,000 & $18,040.72$ \\
\hline$U L_{2}$ & 28,000 & $28,335.54$ \\
\hline$U L_{3}$ & 55,000 & $43,890.70$ \\
\hline$U L_{4}$ & 75,000 & $59,445.85$ \\
\hline$m_{1}$ & 8,000 & $12,683.89$ \\
\hline$m_{2}$ & 7,500 & $11,121.71$ \\
\hline$m_{3}$ & 7,750 & $12,287.51$ \\
\hline$m_{4}$ & 4,800 & $7,610.26$ \\
\hline$a_{1}$ & 502 & $1,521.88$ \\
\hline$a_{2}$ & 470 & $1,298.79$ \\
\hline$a_{3}$ & 486 & $1,498.58$ \\
\hline$c_{i}^{2 S p}$ & 800 & 712.46 \\
\hline$u$ & 110 & 0.01 \\
\hline$w$ & 40,000 & $35,739.57$ \\
\hline$k$ & 80,000 & $78,143.40$ \\
\hline$c_{i}^{2 O p}$ & 750 & 768.85 \\
\hline$C_{i}^{2 H p 1}$ & 800 & 768.86 \\
\hline$C_{i}^{2 H p 2}$ & 900 & $1,845.90$ \\
\hline$c_{i}^{2 \mathrm{Hp} 3}$ & 1,000 & $1,845.91$ \\
\hline$c_{i}^{2 \mathrm{Hp} 4}$ & 1,100 & 2,922.96 \\
\hline$q$ & 95,000 & 95,000 \\
\hline$e$ & 15,000 & 15,000 \\
\hline$c_{i}^{2 H F}$ & 1,200 & 0.04 \\
\hline Tenants 1 & 300 & 636.98 \\
\hline Tenants 2 & 150 & 282.60 \\
\hline Tenants 3 & 992 & $1,205.97$ \\
\hline Expenditures 1 & 0.19 & 0.1887119 \\
\hline Expenditures 2 & 0.36 & 0.4239699 \\
\hline
\end{tabular}

Source: Own elaborations based on BI-SHIW. 
Table 4: The composition of the tax cut by income classes

\begin{tabular}{|c|c|c|c|c|c|c|c|}
\hline $\begin{array}{c}\text { Income class } \\
\text { (thousand euros) }\end{array}$ & $\begin{array}{l}\text { Winner } \\
(\%)\end{array}$ & $\begin{array}{c}\text { Indifferent } \\
(\%)\end{array}$ & $\begin{array}{l}\text { Loser } \\
(\%)\end{array}$ & $\begin{array}{c}\text { Total } \\
(\%)\end{array}$ & $\begin{array}{l}\text { Average win } \\
\text { (euros) }\end{array}$ & $\begin{array}{c}\text { Average loss } \\
\text { (euros) }\end{array}$ & $\begin{array}{l}\text { Composition of } \\
\text { the tax cut (\%) }\end{array}$ \\
\hline $0-8$ & 5.91 & 19.44 & 0.00 & 25.35 & 82.6 & 9.5 & 1.93 \\
\hline 8-15 & 17.26 & 4.68 & 0.00 & 21.94 & 659.1 & 0.0 & 44.90 \\
\hline $15-28$ & 34.84 & 0.44 & 0.06 & 35.35 & 323.0 & 5.6 & 44.43 \\
\hline $28-55$ & 12.65 & 0.02 & 0.85 & 13.52 & 115.6 & 27.3 & 5.68 \\
\hline $55-75$ & 2.19 & 0.00 & 0.00 & 2.19 & 297.5 & 0.0 & 2.57 \\
\hline above 75 & 1.65 & 0.00 & 0.01 & 1.65 & 77.4 & 473.3 & 0.49 \\
\hline Total & 74.50 & 24.58 & 0.92 & 100.00 & 340.4 & 28.9 & 100.00 \\
\hline
\end{tabular}


Table 5: Inequality indexes for taxpayers

\begin{tabular}{lcccc}
\hline \hline \multicolumn{1}{c}{ Index } & Present value & Best value & $\begin{array}{c}\text { Absolute } \\
\text { difference }\end{array}$ & $\begin{array}{c}\text { Percentage } \\
\text { difference }\end{array}$ \\
\hline \hline Gini coefficient for the gross income & 0.4433803 & 0.4433803 & 0.0000000 & 0.0 \\
\hline Gini coefficient for the net income & 0.3913966 & 0.3859490 & -0.0054476 & -1.4 \\
\hline Concentration coefficient for the net income & 0.3907739 & 0.3853523 & -0.0054216 & -1.4 \\
\hline Gini coefficient for the net tax liability & 0.6815444 & 0.7282375 & 0.0466931 & 6.9 \\
\hline Concentration coefficient for the net tax liability & 0.6721563 & 0.7190638 & 0.0469075 & 7.0 \\
\hline Redistributive effect & 0.0519837 & 0.0574313 & 0.0054476 & 10.5 \\
\hline Reynolds-Smolensky index & 0.0526064 & 0.0580280 & 0.0054216 & 10.3 \\
\hline Kakwani index & 0.2287760 & 0.2756835 & 0.0469075 & 20.5 \\
\hline Atkinson-Plotnik-Kakwani index & 0.0006227 & 0.0005967 & -0.0000260 & -4.2 \\
\hline Average tax rate & 0.1869570 & 0.1738869 & -0.0130701 & -7.0 \\
\hline \hline
\end{tabular}




\section{DEPARTMENT OF ECONOMICS AND STATISTICS \\ UNIVERSITY OF TORINO}

Corso Unione Sovietica 218 bis - 10134 Torino (ITALY)

Web page: http://esomas.econ.unito.it/ 